\title{
Evaluating and Optimizing Transnational Grid Construction Based on Input-Output Analysis under the Background of Global Energy Interconnection
}

\author{
Jinying Li, Jing Xiang* \\ Department of Economics and Management, North China Electric Power University, Baoding, Lianchi District, \\ Baoding City, Hebei Province, China
}

Received: 29 August 2019

Accepted: 15 November 2019

\begin{abstract}
In order to integrate the evaluation and optimization of transnational power grid projects and to quantify the adjustment of energy interconnection schemes, this paper improved the Min DS (minimum distance to strong efficiency frontier) DEA (data envelopment analysis) model and combined it with gray correlation analysis, which can measure the input-output efficiency and quantify and screen the optimization paths. Taking 10 transnational power grid projects and the Asian Energy Internet Program for case analysis, the study found that the input-output efficiency of the third schemes of China's Xinjiang-Pakistan Project is the highest (2.792). For the Southeastern Tibet-Bang Mumbai Project, there is 1047.368-million-yuan investment cost redundancy. The input-output efficiency of Northeast Asia, Southeast Asia and China in 2050 is lower than that of 2030. On the basis of the Asia Energy Interconnection Program in 2030, North-Central Asia, West Asia and South Asia should increase $\mathrm{CO}_{2}$ emissions reduction by $0.750,0.396$ and 0.236 million tons respectively. North-Central Asia, West Asia and South Asia should build more hydro-power, wind energy and solar energy power generation bases respectively in order to achieve this adjustment. This work can provide a tool for the evaluation and optimization of transnational power grid project decision makers and energy interconnection scheme planners.
\end{abstract}

Keywords: transnational power grid construction, data envelopment analysis, gray correlation analysis, energy interconnection

*e-mail: ncepu_xj@163.com 


\section{Introduction}

Resource constraints, environmental pollution, and climate change are the three major challenges facing the world's energy development. Since the United Nations Framework Convention on Climate Change [1], the Kyoto Protocol [2] and other agreements have been reached, the international community has been exploring effective international cooperation models for climate change mitigation [3]. Resource waste, environmental pollution and the global greenhouse effect are becoming increasingly serious, making the coordinated development of the economy and environment a new global initiative [4]. Building a global energy internet which sets clean energy as the mainstay and electricity as the center provides a new solution for efficient and sustainable development of energy [5]. In recent years, many power companies have been involved in the construction and operation of overseas power projects [6]. By the end of 2015, 50 countries in 64 core countries along the "Belt and Road" have built up transnational transmission lines [7]. The Global Energy Internet Backbone Network Research report predicts that total investment of the global energy internet will be about 38 trillion US dollars and the global installed capacity in 2030 and 2050 will reach 15.7 billion $\mathrm{kW}$ and 26.7 billion $\mathrm{kW}$ respectively [8].

With the development of a transnational power grid, more and more scholars have been studying the evaluation and optimization of transnational power grid projects based on the research of domestic projects. Büyüközkan G. and Karabulut Y. applied two multicriteria decision making (MCDM) techniques to study a thermal power and three renewable energy projects: analytic hierarchy process (AHP) and VIKOR(MCDM) [9]. Based on the evaluation results of the improved TOPSIS, Niu D., Li Y. and Dai S. used the modified fly optimization algorithm (MFOA) to effectively evaluate the sustainability of power grid construction projects [10]. Ma L., Chen H. and Yan H. combined the matterelement extension theory (MEET) and the attribute hierarchical model (AHM) to develop an evaluation model for distributed generation projects [11]. However, the above research is not fully applicable to transnational power grid projects. From the perspective of different stakeholders, Zhao Y., Xiang J. and Xu J. improved the matter-element extension model with gray relational projection value in order to realize comprehensive benefit evaluation of transnational power grid projects [12]. To complete a dynamic evaluation of transnational power grid projects, Li J. and Xu J. combined TOPSIS (technique for order preference by similarity to an ideal solution), the gray correlation analysis method and the vector projection method to overcome the limitation of the one-way evaluation [13]. Nevertheless, there are still some problems in the efficiency study of transnational energy interconnection planning and projects. On the one hand, research on energy interconnection schemes is mostly from the perspective of planning-design and most of the scheme's optimization models focus on the parameters of multi-energy equipment [14-16]. On the other hand, the transnational power grid projects evaluation study only obtains the benefit result, but does not provide specific ways to improve project efficiency.

To solve the above problems, DEA has been gradually applied in power grid project evaluation research. He Y., Liu W. and Jiao J. applied the CCRDEA model to analyze the efficiency of power grid projects [17]. Sağlam Ü. evaluated the efficiencies of the 236 large utility-scale wind farms using BCC models [18]. However, the traditional DEA model has some limitations. Therefore, the DEA model is constantly improved. Sueyoshi T., Li A. and Gao Y. compared the differences of three DEA approaches (i.e., radial, non-radial and intermediate approaches) and examined the performance of Chinese fossil fuel power plants [19]. Wu T., Chen Y. and Shang W. proposed a nonradial DEA approach to measure energy and solved the problem that formulates national policies based solely on environmental aspects [20]. Zhang Y., Sun Y. and Huang J. adopted the meta-frontier nonradial directional distance function based on the DEA window analysis to explore the efficiency evolution and technology gaps [21]. Based on the least distance to the Pareto-efficient frontier (Min DS) model, Aparicio J. and Ruiz J. proposed a new method to measure productivity change of DMUs in the full input-output space [22]. Then Aparicio J., Garcia N. and Kapelko M. applied the Min DS model to identify different levels of inefficiency [23]. To achieve the further division of effective units, Piao S. and Li J. estimated the environmental efficiency of China based on the super-efficiency DEA model [24]. However, the choice of efficiency improvement methods is still unsolved. Tao M. pointed out that how to grasp the key factors and implement adjustment to improve efficiency is a very key issue [25]. In order to give reasonable suggestions to improve the efficiency of equity financing, the gray correlation analysis method was used to analyze its influencing factors [26]. Zhou Y., Jia F. and Lü H. used gray correlation analysis to determine the priority level of efficiency-enhancing measures in the study of China's global innovation indicator [27].

In order to make up for the gap between energy planning and the evaluation and optimization of transnational power grid construction projects, and to solve the problem of the selection of optimization path, this paper improves the combination of the Min-DS DEA model and super efficiency model. The improved DEA model not only further compares the effective units, but also quantifies the ways to improve efficiency. The application of grey correlation analysis can explore the key ways to improve the efficiency of transnational power grid construction planning, and provides suggestions for the improvement of transnational power grid construction planning. 


\section{Materials and Methods}

\section{Improved Super-Efficient Min DS DEA Model}

Based on the SBM (slack based measure) model [28] and traditional Min DS DEA model [22], this paper combined the improved Min DS DEA model with the super-efficient DEA model [29]. The improved superefficient Min DS DEA model is:

$$
\begin{gathered}
\max \frac{1-\frac{1}{m} \sum_{i=1}^{m}\left(\frac{s_{i}^{-}}{x_{i k}}\right)}{1+\varepsilon \frac{1}{q} \sum_{r=1}^{q}\left(\frac{s_{r}^{+}}{y_{r k}}\right)} \\
\text { s.t. } \sum_{j \in E} x_{i j} \lambda_{j}+s_{i}^{-}=x_{k}, i=1,2, \ldots, m \\
\sum_{j \in E} y_{r j} \lambda_{j}-s_{r}^{+}=y_{k}, r=1,2, \ldots, q \\
\sum_{r=1}^{q} \mu_{r} y_{r j}-\sum_{i=1}^{m} v_{i} x_{i j}+d_{j}=0, j \in E \\
v_{i}, \mu_{r}, s_{i}^{-}, s_{r}^{+} \geq 0, i=1,2, \ldots, m ; r=1,2, \ldots, q \\
0 \leq d_{j} \leq M b_{j}, j \in E, j \neq k \\
0 \leq \lambda_{j} \leq M\left(1-b_{j}\right), j \in E \\
b_{j} \in\{0,1\}, j \in E
\end{gathered}
$$

Suppose there are $\mathrm{n}$ decision-making units recorded as $\operatorname{DMU}_{\mathrm{j}}(\mathrm{j}=1,2, \ldots, \mathrm{n})$. Each DMU has $\mathrm{m}$ kinds of inputs denoted as $\mathrm{x}_{\mathrm{i}}(\mathrm{i}=1,2, \ldots, \mathrm{m})$ and has $\mathrm{q}$ kinds of outputs denoted as $\mathrm{y}_{\mathrm{r}}(\mathrm{r}=1,2, \ldots, \mathrm{q}) . \mathrm{s}_{\mathrm{i}}^{-}$and $\mathrm{s}_{\mathrm{r}}^{+}$ represent the slack variables of input and output indicators respectively. The input and output weights are expressed as $v_{i}(i=1,2, \ldots, m)$ and $u_{r}(r=1,2, \ldots$, q) respectively. The DMU currently being measured is recorded as $\mathrm{DMU}_{\mathrm{k}}$ and $\rho$ represents the efficiency value of the evaluated DMU. Let $t=\frac{1}{\sum_{i=1}^{m} v_{i} x_{i k}}, \mu=\mathrm{t} u, v=$ $t v, \mathrm{M}$ is a sufficiently large positive number and $\varepsilon$ is non-Archimedean infinitesimal. $\mathrm{E}$ is the set of effective DMUs determined in the SBM model and $\lambda$ is the linear combination coefficient of DMU. Assuming that $s_{r}^{+^{*}}$ is the optimal solution of the above model, the outputoriented minimum distance function efficiency value is expressed as $\rho_{k}^{o}=\frac{1}{1+\frac{1}{q} \sum_{r=1}^{q}\left(\frac{s_{r}^{+*}}{y_{r k}}\right)}$.

\section{Gray Correlation Analysis}

Gray correlation analysis uses the gray correlation degree to describe the degree of correlation between factors [30]. The steps of calculating the correlation degree are divided into four steps:

1. Determine the reference sequence and the comparison sequence. Reference sequence is inputoutput efficiency sequence represented by $C_{i}(k)$. Comparison sequence is input-output indicators sequences represented by $C_{j}(k)$.
2. Make the reference sequence and the comparison sequences dimensionless and represented by $C_{i}^{\prime}(k)$, $C_{j}^{\prime}(k)$ respectively.

3. Calculate the absolute difference sequence $\Delta_{i}(\mathrm{k})$ :

$$
\Delta_{\mathrm{i}}(\mathrm{k})=\mathrm{C}_{\mathrm{i}}{ }^{\prime}(\mathrm{k})-\mathrm{C}_{\mathrm{j}}{ }^{\prime}(\mathrm{k})
$$

4. Calculate correlation degree:

$$
\xi_{i}(\mathrm{k})=\frac{\Delta(\min )+\tau \Delta(\max )}{\Delta_{\mathrm{i}}(\mathrm{k})+\tau \Delta(\max )}
$$

Among them, $\Delta(\max )$ and $\Delta(\min )$ are the maximum and minimum values in $\Delta_{i}(\mathrm{k})$ respectively and $\tau$ is the resolution coefficient; the value is between $(1,0)$, generally 0.5 . The correlation degree calculation formula is as follows:

$$
R_{i}=\frac{1}{m} \sum_{k=1}^{m} \xi_{i}(k), k=1,2, \ldots, m
$$

\section{Input and Output Indicators of Transnational Power Grid Projects}

\begin{tabular}{|c|c|c|}
\hline \multicolumn{2}{|l|}{ Project Name } & DMU \\
\hline \multicolumn{2}{|c|}{ China-Korea-Japan Transmission Project } & 1 \\
\hline \multicolumn{2}{|c|}{ Yunnan-Vietnam Transmission Project } & 2 \\
\hline \multicolumn{2}{|c|}{ Yunnan-Myanmar-Thailand Transmission Project } & 3 \\
\hline \multirow{3}{*}{$\begin{array}{c}\text { Xinjiang-Pakistan Transmission } \\
\text { Project }\end{array}$} & scheme1 & 4 \\
\hline & scheme2 & 5 \\
\hline & scheme3 & 6 \\
\hline \multicolumn{2}{|c|}{ Southeastern Tibet- Bangalore } & 7 \\
\hline \multicolumn{2}{|c|}{ Southeastern Tibet-Bang Mumbai } & 8 \\
\hline \multicolumn{2}{|c|}{ Southeast Tibet-Bangladesh } & 9 \\
\hline \multicolumn{2}{|c|}{ Kazakhstan-China-Pakistan Transmission project } & 10 \\
\hline \multirow{2}{*}{$\begin{array}{c}\text { Tianjin-Xibobao Transmission } \\
\text { project }\end{array}$} & scheme1 & 11 \\
\hline & scheme2 & 12 \\
\hline \multirow{3}{*}{$\begin{array}{c}\text { China-Russian Transmission } \\
\text { Project }\end{array}$} & scheme1 & 13 \\
\hline & scheme2 & 14 \\
\hline & scheme3 & 15 \\
\hline
\end{tabular}

This paper selected 10 key projects in the preliminary plan of Asia Energy Internet [31]. Since there are several schemes for some of 10 projects, each scheme in this chapter is regarded as a DMU, so there are 15 DMUs as shown in Table 1. Referring to the actual projects and the research of transnational power grid construction comprehensive benefit [12, 13, 32], this paper chose investment cost, transmission distance, voltage class, arrival price and transmission capacity

Table 1. DMU of transnational power grid projects. 
Table 2. Raw data of transnational power grid projects input-output indicators.

\begin{tabular}{|c|c|c|c|c|c|}
\hline \multirow[b]{2}{*}{ DMU } & \multicolumn{5}{|c|}{ Input indicator } \\
\hline & $\begin{array}{l}\text { Investment cost } \\
\text { (100 million yuan) }\end{array}$ & $\begin{array}{l}\text { Transmission distance } \\
(\mathrm{km})\end{array}$ & Voltage class $(\mathrm{kV})$ & $\begin{array}{l}\text { Arrival price } \\
(\text { yuan } / \mathrm{kW})\end{array}$ & $\begin{array}{c}\text { Transmission } \\
\text { capacity } \\
(10,000 \mathrm{~kW})\end{array}$ \\
\hline 1 & 370 & 830 & 500 & 0.8 & 200 \\
\hline 2 & 212 & 2120 & 800 & 0.47 & 800 \\
\hline 3 & 185 & 1600 & 800 & 0.44 & 800 \\
\hline 4 & 258 & 2510 & 800 & 0.43 & 800 \\
\hline 5 & 237 & 2120 & 800 & 0.42 & 800 \\
\hline 6 & 31 & 600 & 400 & 0.5 & 60 \\
\hline 7 & 293 & 3050 & 800 & 0.45 & 1000 \\
\hline 8 & 296 & 3100 & 800 & 0.45 & 1000 \\
\hline 9 & 108 & 860 & 600 & 0.4 & 500 \\
\hline 10 & 778 & 3470 & 1100 & 0.33 & 2200 \\
\hline 11 & 220 & 1284 & 800 & 0.47 & 8000 \\
\hline 12 & 121 & 1284 & 660 & 0.73 & 4000 \\
\hline 13 & 1597 & 1830 & 800 & 0.58 & 800 \\
\hline 14 & 1279 & 1830 & 800 & 0.44 & 440 \\
\hline 15 & 1144 & 1830 & 660 & 0.42 & 440 \\
\hline \multirow[b]{2}{*}{ DMU } & \multicolumn{5}{|c|}{ Output indicator } \\
\hline & $\begin{array}{c}\text { Electricity price } \\
\text { competitiveness } \\
\text { (yuan / kWh) }\end{array}$ & $\begin{array}{c}\text { Total delivery capacity } \\
\text { (GWh) }\end{array}$ & $\begin{array}{l}\text { Saving standard coal } \\
\text { (million tons) }\end{array}$ & \multicolumn{2}{|c|}{$\begin{array}{l}\mathrm{CO}_{2} \text { reduction } \\
\text { (million tons) }\end{array}$} \\
\hline 1 & 0.27 & 11000 & 3223 & \multicolumn{2}{|c|}{8444} \\
\hline 2 & -0.12 & 44000 & 20152 & \multicolumn{2}{|c|}{52798} \\
\hline 3 & 0.02 & 44000 & 36141 & \multicolumn{2}{|c|}{94689} \\
\hline 4 & 0.24 & 44000 & 19800 & \multicolumn{2}{|c|}{51876} \\
\hline 5 & 0.25 & 44000 & 19800 & \multicolumn{2}{|c|}{51876} \\
\hline 6 & 0.17 & 3300 & 1485 & \multicolumn{2}{|c|}{3891} \\
\hline 7 & 0.07 & 55000 & 22000 & \multicolumn{2}{|c|}{57640} \\
\hline 8 & 0.06 & 55000 & 22000 & \multicolumn{2}{|c|}{57640} \\
\hline 9 & 0.21 & 27500 & 13200 & \multicolumn{2}{|c|}{34584} \\
\hline 10 & 0.34 & 121000 & 54450 & \multicolumn{2}{|c|}{142659} \\
\hline 11 & -0.05 & 440000 & 136400 & \multicolumn{2}{|c|}{357368} \\
\hline 12 & -0.31 & 220000 & 68200 & \multicolumn{2}{|c|}{178684} \\
\hline 13 & -0.16 & 44000 & 13640 & \multicolumn{2}{|c|}{35737} \\
\hline 14 & -0.02 & 24200 & 7502 & \multicolumn{2}{|c|}{19655} \\
\hline 15 & 0 & 24200 & 7502 & \multicolumn{2}{|c|}{19655} \\
\hline
\end{tabular}

as input indicators, and electricity price competitiveness, total delivery capacity, saving standard coal and $\mathrm{CO}_{2}$ reduction as output indicators. All input-output indicator units and symbols of some slack variables are shown in Table 2. Input-output data are derived from project preliminary planning information and are shown in Table 2. 
Table 3. Raw data of 2030 Asian Energy Internet input-output indicators.

\begin{tabular}{|c|c|c|c|c|}
\hline \multirow{2}{*}{ DMU } & Input indicator & \multicolumn{3}{|c|}{ Output indicator } \\
\cline { 2 - 5 } & $\begin{array}{c}\text { Clean energy generation } \\
(100 \text { million } \mathrm{kWh})\end{array}$ & $\begin{array}{c}\text { Saving standard coal } \\
(10,000 \text { tons })\end{array}$ & $\begin{array}{c}\mathrm{CO}_{2} \text { emission reduction } \\
(100 \text { million tons })\end{array}$ & $\begin{array}{c}\mathrm{SO}_{2} \text { emission reduction } \\
(100 \text { million tons })\end{array}$ \\
\hline Northeast Asia & 11368.27 & 38652.13 & 9.64 & 0.02 \\
\hline North-Central Asia & 14633.69 & 49754.55 & 12.4 & 0.02 \\
\hline West Asia & 17461.31 & 59368.46 & 14.8 & 0.02 \\
\hline South Asia & 17199.84 & 58479.46 & 14.58 & 0.02 \\
\hline Southeast Asia & 4133.69 & 14054.55 & 3.5 & 0.01 \\
\hline China & 56063.48 & 190615.82 & 47.52 & 0.08 \\
\hline
\end{tabular}

\section{Input and Output Indicators of Asia Energy Interconnection Program}

The Global Energy Interconnection Development and Cooperation Organization (GEIDCO) proposed 2030 and 2050 Asian Energy Internet plans [33]. In order to further study regional efficiency differences, this study took Northeast Asia, North-Central Asia, West Asia, South Asia, Southeast Asia and China as DMUs. The input-output analysis of 2030 and 2050 plans were conducted separately in order to observe the time-varying law of input-output efficiency. Input indicator is clean energy generation and output indicators are saving standard coal, $\mathrm{CO}_{2}$ emission reduction and $\mathrm{SO}_{2}$ emission reduction. The input and output data of 2030 and 2050 Asian Energy Internet are in Tables 3 and 4.

\section{Results and Discussion}

\section{Input-Output Analysis Result of Transnational Power Grid Projects}

By using the improved Min DS model, the inputoutput efficiency values of 15 DMUs are shown in Fig. 1, which clearly shows that input-output efficiency of 15 DMUs are different, which confirmed that the model conduced in this paper can avoid the problem mentioned in the introduction that the effective units cannot be further compared. On the one hand, the efficiency values of three schemes of Xinjiang-Pakistan Transmission Project (DMU 4, 5 and 6) are 0.933, 1.040 and 2.792 respectively. Similarly, DMU 11 and 12, which represent the two schemes of the Tianjin-Xibobao Project, have efficiency values of 1.266 and 1.306 , respectively. That is to say, this model can provide reference for the selection of different schemes in the same project from the perspective of input-output efficiency. On the other hand, this figure also shows the input-output efficiency values of different projects and the gap between them. Assuming that multi-scheme projects choose the most efficient input-output scheme, we can compare the inputoutput efficiency of these 10 transnational power grid projects. The top three projects in input-output efficiency are the Yunnan-Myanmar-Thailand Transmission Project, the Kazakhstan-China-Pakistan Transmission project and the Tianjin-Xibobao Project.

In addition to the input-output efficiency value, the slack variables corresponding to each DMU inputoutput indicator are shown in Fig. 2. From the view of input, DMU 14 and 15 have large slack variable in investment cost, transmission distance and voltage class. Decision makers should further reduce investment costs - especially by re-selecting sending end and receiving terminal to reduce transmission distance.

Table 4. Raw data of 2050 Asian Energy Internet input-output indicators.

\begin{tabular}{|c|c|c|c|c|}
\hline \multirow{2}{*}{ DMU } & Input indicator & \multicolumn{3}{|c|}{ Output indicator } \\
\cline { 2 - 5 } & $\begin{array}{c}\text { Clean energy generation } \\
(100 \text { million } \mathrm{kWh})\end{array}$ & $\begin{array}{c}\text { Saving standard coal } \\
(10,000 \text { tons })\end{array}$ & $\begin{array}{c}\mathrm{CO}_{2} \text { emission reduction } \\
(100 \text { million tons })\end{array}$ & $\begin{array}{c}\mathrm{SO}_{2} \text { emission reduction } \\
(100 \text { million tons })\end{array}$ \\
\hline Northeast Asia & 16900.79 & 57462.7 & 14.33 & 0.02 \\
\hline North-Central Asia & 24939.23 & 84793.39 & 21.14 & 0.03 \\
\hline West Asia & 31095.99 & 105726.36 & 26.36 & 0.04 \\
\hline South Asia & 43940.06 & 149396.19 & 37.24 & 0.06 \\
\hline Southeast Asia & 12219.02 & 41544.68 & 10.36 & 0.02 \\
\hline China & 110707.07 & 376404.03 & 93.84 & 0.15 \\
\hline
\end{tabular}




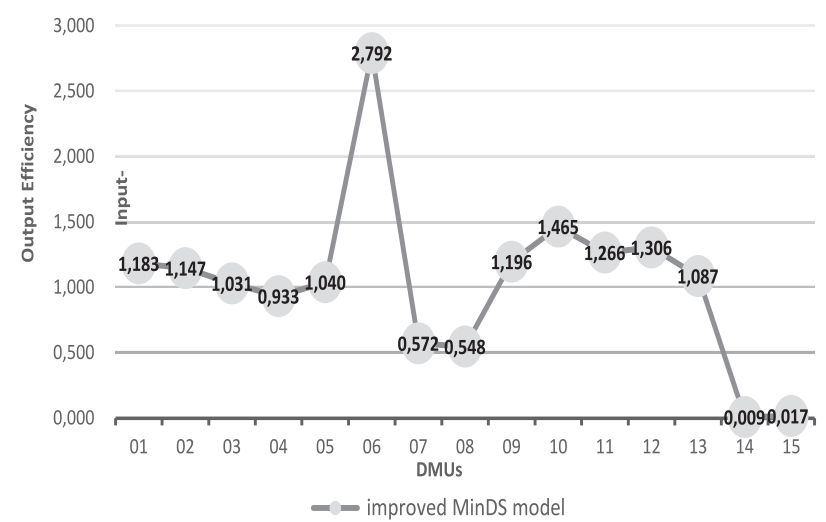

Fig. 1. Input-output efficiency of transnational power grid projects.

Evaluating transmission technology rationally to select the appropriate voltage class should also be considered. From the slack variable result of arrival price shown in Fig. 2, we can see that the arrival prices of DMUs 7, 8 , and 14 are higher than the target value. The arrival price can be reduced by further strengthening resource scheduling, schedule management and reducing operating costs. DMU4 has slack variables on the inputs of transmission distance and voltage class. The input improvement for DMU4 is reflected in reducing the voltage class on the premise of meeting the transmission capacity and reducing the transmission distance by changing the transmission line.

For output indicator, DMUs 4, 7, 8, 14 and 15 have slack variables on electricity price competitiveness, which means that their outputs of electricity price competitiveness are lower than the target value. Transmission price (including tax) and line loss price should be reduced in order to increase electricity price competitiveness. The slack variable on $\mathrm{CO}_{2}$ emission reduction are mainly from DMUs $4,7,8,14$ and 15 . Therefore, the Xinjiang-Pakistan Transmission Project, Southeastern Tibet- Bangalore, Southeastern TibetBang Mumbai and China-Russian Transmission Project should increase clean energy generation in order to increase $\mathrm{CO}_{2}$ emission reduction.

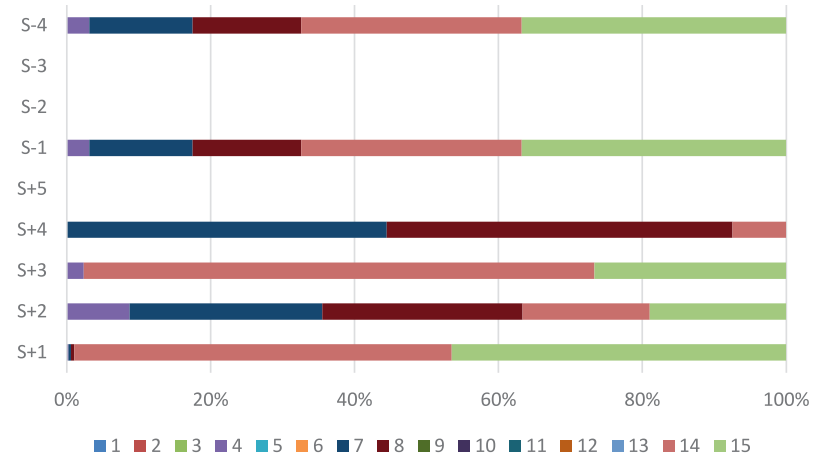

Fig. 2. Percentage stacking diagram of slack variables in transnational power grid projects.

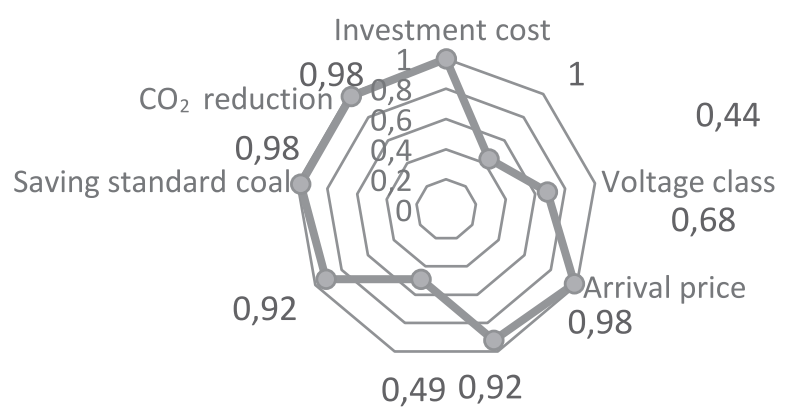

Fig. 3. Gray correlation degree between input-output indicators and input-output efficiency.

\section{Gray Correlation Analysis of Input-Output Indicators and Efficiency}

In order to explore the impact of each input-output indicator change on the efficiency value for each DMU, this chapter calculates the gray correlation degree between input-output indicator and efficiency of each DMU.

Taking DMU 8 as an example, the results of gray correlation degree are shown in Fig. 3. The gray correlation degree between investment cost and inputoutput efficiency is the highest. The gray correlation degrees between arrival price and efficiency, between saving standard coal and efficiency and between saving standard coal and efficiency are 0.98. The gray correlation degrees of between electricity price competitiveness and efficiency and between transmission distance and efficiency are lower than average gray correlation degree between input-output index and efficiency. Fig. 2 shows that for DMU8, the input of investment cost, transmission distance and arrival price need to be reduced and the output of electricity price competitiveness and $\mathrm{CO}_{2}$ reduction need to be increased. According to the result of gray correlation degree in Fig. 3, DMU8 should first adjust investment cost, followed by arrival price and $\mathrm{CO}_{2}$ reduction.

\section{Input-Output Efficiency of Asia Energy Internet in 2030 and 2050}

The input-output efficiency of Asian Energy Internet in 2030 and 2050 was carried out by an improved super-efficient Min DS model. The efficiency values are shown in Fig. 4, which not only shows the inputoutput efficiency differences in Northeast Asia, Central and North Asia, West Asia, South Asia, Southeast Asia, and China, but also reveals the input-output efficiency changes between 2030 and 2050 .

From the perspective of regional input-output efficiency differences, the input-output efficiency values in Southeast Asia and China are higher than that of other regions. The high input-output efficiency of China echoes its pivotal and platform role in the Asian energy 


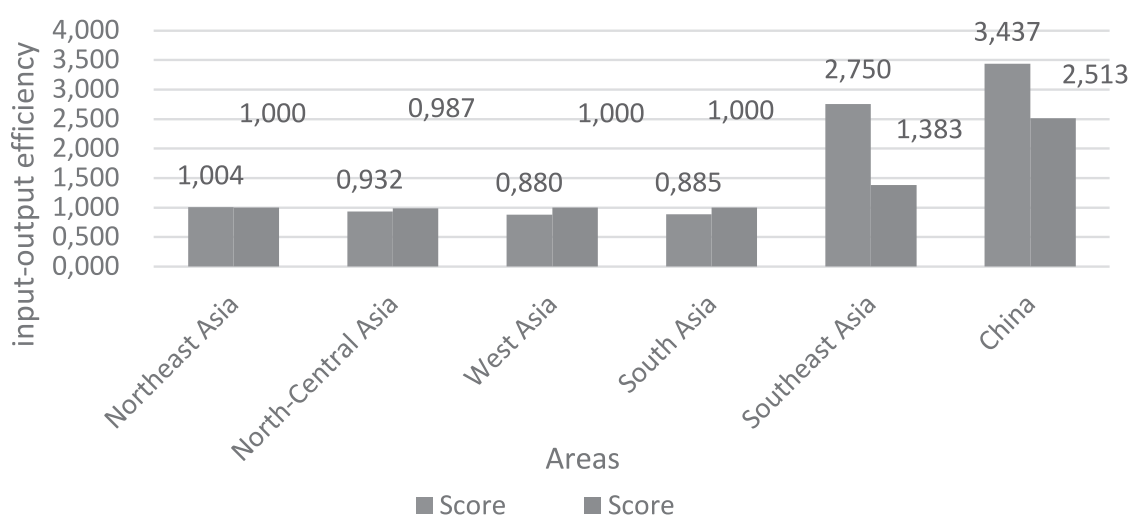

Fig. 4. Input and output efficiency of Asian Energy Internet.

internet. According to the Asian energy Internet plan (Liu Z., 2017), in 2030 China will form an asynchronous interconnection with Northeast Asia, Central and North Asia, East West Asia, South Asia and Southeast Asia. In 2050 China will maintain asynchronous interconnection and will form synchronous interconnection with Southeast Asia. Compared with other regions, Southeast Asia has a good grid interconnection foundation, which is consistent with the input-output efficiency of Southeast Asia. In 2030, Southeast Asia will form a synchronous grid structure, connecting the main load centers, large coal-fired and hydro-power bases in the region. Southeast Asia will synchronously interconnect with the UHV power grid in southern China in 2050. Southeast Asia is rich in hydro-power resources, with 108 million kilowatts of technology installed. Therefore, the high efficiency of Southeast Asia is also related to the abundant water resources and the satisfaction of evacuation and absorption needs for imported electricity.

Fig. 4 shows that the input-output efficiencies of Northeast Asia, Southeast Asia and China declined in 2050 compared with that of 2030, while the inputoutput efficiency of North-Central Asia, West Asia and South Asia improved. Russia, Mongolia and Kazakhstan in North-Central Asia are rich in clean energy resources. They are suitable for building largescale wind and solar power bases, so their advantages in energy interconnection are gradually highlighted. In 2030, the planning of interconnection in West Asia will focus on improving the regional interconnection of power grids. In 2050, all countries in this region will achieve extensive interconnection through UHV AC. In 2030, the South Asian Subcontinent initially will build a synchronous AC interconnection covering the whole region. In 2050, it will maintain an asynchronous interconnection pattern with China. Therefore, the improvement of input-output efficiency in Central and North Asia, West Asia and South Asia is closely related to the expansion of interconnection scale and the construction of a clean energy base. In 2030, clean energy generation in China accounted for 0.464 of the total clean energy generation in Asia, and by 2050 the ratio will have dropped to 0.462 , which may be a reason for the decline of input-output efficiency in China. The decline of input-output efficiency in Southeast Asia may be caused by the improvement of input-output efficiency in other regions.

\section{Emission Reduction Potential Analysis of Asia Energy Internet in 2030 and 2050}

The larger the slack variable of $\mathrm{CO}_{2}$ emission reduction, the larger the gap between $\mathrm{CO}_{2}$ emission reduction and the target value. That is to say, there is still a lot of room for improvement in the output of $\mathrm{CO}_{2}$ emission reduction. Fig. 5 shows that in 2030 the slack variable of $\mathrm{CO}_{2}$ emission reduction in NorthCentral Asia, West Asia and South Asia will be 0.750 million tons, 0.396 million tons and 0.236 million tons, respectively. In 2050 the slack variable of $\mathrm{CO}_{2}$ emission reduction in North-Central Asia and West Asia will have dropped to 0.336 million tons and 0.173 million tons, respectively. In 2050 the slack variable of $\mathrm{CO}_{2}$ emission reduction in South Asia will rise to 0.774 million tons. South Asia's hydro-power resources are also very rich, with installed capacity of technology of about 366 million kilowatts. Therefore, in order to increase the output of $\mathrm{CO}_{2}$ emission reduction,

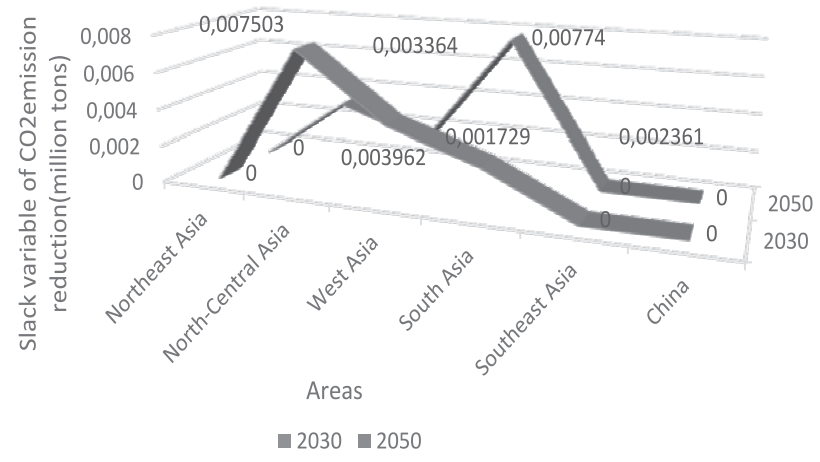

Fig. 5. Slack variable of $\mathrm{CO}_{2}$ emission reduction in Asian Energy Internet. 
renewable energy power generation, especially hydropower, should be further increased in South Asia in the future. There are abundant wind energy resources in North-Central Asia. The installed capacity of wind energy is about 6.7 billion kWh. For North-Central Asia, building a large wind power base can increase $\mathrm{CO}_{2}$ emission reduction while improving the utilization of bio-energy in the region. Compared with other parts of Asia, West Asia has abundant solar energy resources. Its total installed capacity is 1.406 billion $\mathrm{kWh}$. Therefore, Western Asia should build a large-scale solar energy base to achieve $\mathrm{CO}_{2}$ emission reduction. From the overall point of view of the system, the current investment and output efficiency of Asian power interconnection mainly depends on the interconnection basis and technology level. In the future, the further development and utilization of renewable resources will further promote carbon emission reduction in Asia. Carbon emission reduction benefits from renewable resources will be distributed to all regions of Asia through power interconnection.

\section{Discussion}

This paper improves the Min DS model and combines gray correlation analysis to achieve the project evaluation and quantification of indicator improvement. The input-output efficiency, slack variables and gray correlation degree between input-output indicators and efficiency of each project scheme are obtained in the case study, which verifies that this study is applicable to the transnational power grid projects evaluation, projects efficiency optimization and optimization path screening. In this paper, the input-output analysis of Asia Energy Internet planning shows the difference of inputoutput efficiency among regions, analyses the potential of energy saving and emission reduction in each region, and gives specific targets and suggestions for improving carbon emission reduction in these areas. The analysis of the current situation and future development trend of power interconnection in different regions of Asia is helpful for further explaining differences in the output efficiencies of grid interconnection projects in different regions. Through the analysis, we find that the input-output efficiency of China and Southeast Asia is higher than that of other regions because of its good power interconnection foundation and position of interconnection hub. We cannot ignore the fact that with the development and utilization of clean energy such as wind energy and solar energy in Central and Western Asia, the input-output efficiency will be improved. The improvement of input-output efficiency in South Asia depends on the expansion of its interconnection scale. These conclusions are consistent with the current situation and the future development trend of energy development in Asia. This study makes up for the gap in the evaluation and adjustment of energy interconnection planning.

\section{Conclusions}

The input-output analysis and gray correlation analysis of 10 transnational power grid projects show that the third scheme of the Xinjiang-Pakistan power grid project has the highest input-output efficiency (2.792) and the primary goal of Southeastern TibetBang Mumbai Project efficiency improvement is to decline investment cost by 1047.368 million yuan. In 2030 and 2050, Southeast Asia and China are the regions with high input and output efficiency of energy interconnection. The input and output efficiency of energy interconnection in North-Central Asia, West Asia and South Asia in 2030 is higher than that in 2050. Except for the planned construction of transnational power grids, the increased target of $\mathrm{CO}_{2}$ emission reduction for North-Central Asia in 2030 is 0.750 million tons, the increased target in 2050 is 0.336 million tons. The increased targets of West Asia in 2030 and 2050 are 0.396 and 0.173 million tons, respectively. In South Asia, the increased targets in 2030 and 2050 are 0.236 and 0.774 million tons, respectively. Therefore, in order to increase the output of carbon dioxide emission reduction, South Asia should further increase renewable energy power generation - especially hydropower generation. For the northern region of Central Asia, the construction of a large-scale wind power base can improve the utilization rate of bioenergy in the region and increase carbon dioxide emission reduction. Western Asia should establish large-scale solar energy bases in order to reduce carbon dioxide emissions.

\section{Acknowledgements}

This work was supported by a science and technology project of the State Grid Corporation of China ("Research on comprehensive evaluation method of economic, social and environmental benefits of the Transnational Power Grid Interconnection project").

\section{Conflict of Interest}

The authors declare no conflict of interest.

\section{References}

1. TURNER B. United Nations Framework Convention on Climate Change. Review of European Community \& International Environmental Law. 1 (3), 270, 2010.

2. GRUBB M., VROLIJK C., BRACK D. Kyoto protocol: a guide and assessment. Molecular Ecology. 13 (8), 2121, 1999.

3. DONG C., DONG X., JIANG Q., et al. What is the probability of achieving the carbon dioxide emission targets of the Paris Agreement? Evidence from the top ten emitters. Science of the Total Environment. 1294, 622, 2018. 
4. LI T., LIU N., ZHANG Q. System Dynamics Research on Economic Transformation and Environmentally Coordinated Development in China's Eastern Coastal Region. POLISH JOURNAL OF ENVIRONMENTAL STUDIES. 28 (5), 3569, 2019.

5. LIU Z. Global Energy Internet. China Electric Power Press, Beijing, 2015.

6. XU Z., XUE Y., ZHANG Z. VSC-HVDC Technology Suitable for Bulk Power Overhead Line Transmission. J. Proceedings of the CSEE. 34 (29), 5051, 2014.

7. LIANG C., GAO G., YANG S. et al. "The Belt and Road" Area Power Grid Interconnection Trend Analysis and Promotion Strategy. Journal of Global Energy Interconnection. 1 (S1), 228, 2018.

8. GUANG M. Promote the construction of a global energy interconnection system. Electric Power Equipment Management. 11, 23, 2018

9. BÜYÜKÖZKAN G., KARABULUT Y. Energy project performance evaluation with sustainability perspective. Energy. 119, 549, 2017.

10. NIU D., LI Y., DAI S., et al. Sustainability Evaluation of Power Grid Construction Projects Using Improved TOPSIS and Least Square Support Vector Machine with Modified Fly Optimization Algorithm. Sustainability. 10 (1), 231, 2018

11. MA L., CHEN H., YAN H., et al. Post Evaluation of Distributed Energy Generation Combining the Attribute Hierarchical Model and Matter-Element Extension Theory. Journal of Cleaner Production. 184, 503, 2018.

12. ZHAO Y., XIANG J., XU J., et al. Study on the Comprehensive Benefit Evaluation of Transnational Power Networking Projects Based on Multi-Project Stakeholder Perspectives. Energies. 12 (2), 1, 2019.

13. LI J., XU J., TAN X. Dynamic Comprehensive Benefit Evaluation of the Transnational Power Grid Interconnection Project Based on Combination Weighting and TOPSIS gray Projection Method. Sustainability. 10 (12), 4672, 2018.

14. SONG X., DAI Y., ZHAO Z. et al. Planning Technical Framework and Research Direction of Global Energy Interconnected Power Grid Development. Electric Engineering. 09, 7, 2018.

15. ZHANG S., HU W., WEI Z. et al. Stochastic optimal power flow of integrated power and gas energy system based on chance-constrained programming. Electric Power Automation Equipment. 38 (09), 121,2018.

16. LI S., SHE J. Research on Intelligent Distribution Network Planning and Evaluation Method Based on Energy Interconnection. Electrotechnical Application. 37 (15), 87, 2018.

17. HE Y., LIU W., JIAO J., et al. Evaluation method of benefits and efficiency of grid investment in China: A case study. Engineering Economist. 63 (1), 2018.

18. SAĞLAM Ü. Assessment of the Productive Efficiency of Large Wind Farms in the United States: An Application of Two-Stage Data Envelopment Analysis. Social Science Electronic Publishing. 153, 188, 2017.
19. SUEYOSHI T., LI A., GAO Y. Sector Sustainability on Fossil Fuel Power Plants across Chinese Provinces: Methodological Comparison among Radial, Non-radial and Intermediate Approaches under Group Heterogeneity. Journal of Cleaner Production. 187, 819, 2018.

20. WU T., CHEN Y., SHANG W., et al. Measuring energy use and $\mathrm{CO}_{2}$, emission performances for APEC economies. Journal of Cleaner Production. 183, 590, 2018.

21. ZHANG Y., SUN Y., HUANG J. Energy efficiency, carbon emission performance, and technology gaps: Evidence from CDM project investment. Energy Policy. 115, 119, 2018.

22. APARICIO J., RUIZ J. SIRVENT I. Closest targets and minimum distance to the Pareto-efficient frontier in DEA. Journal of Productivity Analysis. 28 (3), 209, 2007.

23. APARICIO J., GARCIA N., KAPELKO M., et al. Graph Productivity Change Measure Using the Least Distance to the Pareto-Efficient Frontier in Data Envelopment Analysis. Omega. 72, 1, 2017.

24. PIAO S., LI J. Research on Spatial and Temporal Differences of Regional Environmental Efficiency in China Based on Super Efficiency DEA Model. Journal of Arid Land Resources and Environment. 32 (04), 1, 2018.

25. TAO M. Evaluation of Investment Efficiency of Environmental Governance in China and Its Key Influencing Factors. Resources and Environment in the Yangtze Basin, 21 (01), 111, 2012.

26. JIANG X., MA J. Financing efficiency of stock rights of listed companies of water industry and its influencing factors. Journal of Economics of Water Resources. 35 (03), 26-30+74+76, 2017.

27. ZHOU Y., JIA F., LÜ H. Comparative Study on the Influencing Factors of GII Indicator in China Based on the gray Correlation Analysis of Progressive Period. Science and Technology Management Research. 39 (02), 1, 2019.

28. TONE K. A slacks-based measure of super-efficiency in data envelopment analysis. J. European Journal of Operational Research. 143 (1), 32, 2002.

29. ANDERSEN, PETERSEN, CHRISTIAN N. A procedure for ranking efficient units in data envelopment analysis. Management Science. 39 (10), 1261, 1993.

30. TSAI M., Hsu. Application of gray Correlation Analysis in Evolutionary Programming for Distribution System Feeder Reconfiguration. IEEE Transactions on Power Systems. 25 (2), 1126, 2010.

31. LIU Z. Research of Global Clean Energy Resource and Power Grid Interconnection. Proceedings of the CSEE. 36 (19), 5103, 2016.

32. ZHAO Y., WU F. Research on the Status of Transnational Networking Project and the Comprehensive Benefits Analysis. A.4th International Conference on Machinery, Materials and Computer (MACMC). 150, 677, 2017.

33. LIU Z. Accelerating the Construction of Energy Internet in Asia. Think Tank Era. 04, 39, 2017. 
